\title{
MODERN PRACTICE OF LEADERSHIP: ITS ROLE AND IMPORTANCE IN THE SUCCESSFUL OPERATION OF THE ORGANIZATION
}

\section{TEIMURAZ SARTANIA}

\section{PHD Student}

Ivane Javakhishvili Tbilisi State University, Georgia

t.sartania@yahoo.com

Abstract. The rapidly accelerating globalization process in the 21st century, advances in technology and science, and other developments related to these processes have posed hitherto unknown challenges to our country's education system. Therefore, at the current stage of the country's development, the main challenge of the Georgian higher education system should be considered to improve the quality of education.

However, the effectiveness of the higher education system depends on a large extent on the optimal distribution and efficient use of monetary resources between the various links and field of the education system.

Based on the study, generalization and research of the above-mentioned issues in the article, the main factors, influencing the development of organizational leadership and educational space in Georgia, were identified.

The aim of this research is to determine the compliance of the Georgian educational system with the international principles and to identify the model of a successful university with a significant impact in this direction. Also, based on the generalization and evaluation of the experience of foreign universities, active use and implementation of leadership strategies in Georgia.

The aim of research is to identify the challenges of the Georgian education system based on the generalization of modern leadership practice.

The object of research is Georgian and foreign educational institutions.

The subject of research is to study and identify the factors that have a positive and negative impact on the development of the Georgian educational system.

The research is based on analysis and synthesis, as well as graphic representation, comparison and other methods.

KEYWORDS: EDUCATION SYSTEM, EDUCATION REFORM, EDUCATIONAL SPACE, HUMAN GAPITAL, LEADERSHIP, MANAGEMENT.

For citation: Saetania, T., (2021). Modern Practice of Leadership: Its Role and Importance in The Successful Operation of The Organization. Globalization and Business. 12, 162-165. https://doi.org/10.35945/gb.2021.12.022

There has always been an interest in leadership practices from the public. People have been trying to figure out the values and qualities that a successful leader must possess. In recent decades, people's interest in effective leadership has grown even more, due to an unequivocal link between the successful functioning of the organization and well-conducted leadership, as well as effective internal organizational activities (Hallinger, 2011).

Rather than talk directly about modern leadership practices and their significance, it is important to clarify what is meant by the term. It can be said that there are many definitions of leadership and maybe every person has a different association when they hear this word. However, it should be noted that in this paper we consider leadership not as a trait but as a process involving a group of people who share a common organizational interest and goals
(Arnold, 2017). We consider leadership as a process when a particular person turns people employed in the organization into accomplices in order to achieve a set goal through joint effort, which will be beneficial for both the organization and the individual people employed in the company. The main function of a leader can be perceived as follows: to motivate the people around him to achieve a common goal and to create the most comfortable working conditions for them (Bolden, 2004).

Thus, leadership is a complex process. The leader has special qualities that stimulate him to motivate other individuals to implement the set strategy. When talking about modern leadership practice, it is important to outline the key features of organizational performance. In this regard, the formation of the culture and vision of the organization is essential. 
In order to be considered as a successful one for an organization, it must be constantly evolving. The foundation of every organization is a person and a group of people who, over time, shape the culture of the organization as a result of their activities. Establishing an organization culture is impossible without a clearly defined vision. One of the main purposes of modern leadership is to establish a common vision, attitudes and common cultural values in organizational activities (Civil Service Bureau, 2020).

However, leadership can be thought of as a process of transformation, when the leader stimulates like-minded people to maximize their potential. However, leadership is a skill based on a person's knowledge and experience.

Leadership can also be seen as a process in which a particular person influences a group of people to achieve a common goal.

However, it should be noted that the relationship between the leader and his followers is not one-sided. Whereas, on the one hand, the leader influences his associates as well as, to some extent he also occurs under the followers' influence, which serves the common goal. Thus, there are similarities and differences between management and leadership.

Proper use of modern approaches to leadership is especially important in the educational field and educational institutions. In 2005, Georgia joined the Bologna Process, which aims to maximize the compatibility of the Georgian educational space with the European space. All above mentioned considered a fundamental change in the existing education system in Georgia (Kikoria et al., 2019). In order to escape from the chaos created in the Georgian educational system in the post-Soviet period, it was extremely important to be actively involved in the Bologna process and to introduce the methods and practices that were actively used in European countries (Lezhava, Amashukeli, 2016).

\section{Basic Concepts and Approaches to Leadership}

Leadership theory is divided into three main types - sign, behavior and situational theories. One of the oldest theories is the "Great Man" Theory. Based on this concept, people are born as leaders. According to the followers of this theory, the starting point of leadership is directly determined by the personality traits and characteristics. This approach is also called the "big personality" theory, based on which, a leader is distinguished from his peers by his abilities and personal qualities. The main characteristics of a leader are intellect, dominance, persuasiveness, high activity and knowledge needed to solve a specific problem (Madanchian et al., 2016).

There are many definitions of a leader. According to Plato, in the role of a true leader is a person who is constantly focused on his own development and progress. Therefore, leadership belongs to the person who, along with the acquisition of knowledge, has the ability to self-realize. Plato considered these individuals to be people who had the ability to foresee eternity (Takala, 1998).

The theory of the leadership sign was explored by the
German sociologist Max Weber. In his view, for a charismatic leader, supernatural and superhuman qualities are remarkable. In view of the all above mentioned, the society expresses special respect and awe towards the leaders of this category (Breuilly, 2011). It is also noteworthy that charismatic leaders are characterized by a desire for power to achieve a goal.

Kurt Levine, based on his research on the decisionmaking style, distinguishes between a group of authoritarian, democratic, and liberal leaders (Billig, 2014).

As usuall, any organization, depending on its strategy, with the support of the leader tries to deal with the challenges facing him. In particular, it assumes responsibility for the implementation of a strategy, solving the problems of its subordinates, conducting negotiations, acting as an arbitrator, reaching a consensus and etc.

In the process of implementing the organization's strategy, the leader as a manager has the following key functions:

- Be constantly informed about current processes;

- Forming a common organizational vision and culture that ensures sustainable development and successful functioning of the organization;

- Adapting to constantly changing environmental conditions and ensuring the introduction of innovations;

- Ease of conflict situations and prevent possible aggravation of the situation;

- Make changes to the strategic plan according to the situation.

When researching the characteristics and regularities of leadership, it is important to identify the characteristics of leaders' behavior, in particular, "employee orientation" and "production orientation". Whereas leaders who are production-oriented consider the fulfillment of the tasks set before them as a top priority. Based on the above mentioned, they consider employees only as a means for achieving a goal. However, as a rule, preference should be given to cooperation orientation, as focusing on employees usually ensures high productivity of team members.

Also of interest is the two-dimensional vision of a leadership style, developed by Ohio State University researchers Robert Blake and James Mouton, based on both "caring for people" and "caring for production" and suggests "employee orientation" and "production orientation". (Cai, Fink, et al., 2019).

\section{Peculiarities of transformational leadership}

Talk of leadership transformation style first began in the late 1970s, and in the early 1990s the latter emerged as one of the main directions of leadership (Eerkens et al., 2010).

Transformational leadership is considered to be the most effective way to meet the challenges of today's fast-changing world, as its essence lies in the fact that organizations are able to quickly adapt to the ever-changing world and select the most effective style of organizational business at the moment. 
Transformational leadership style focuses on restructuring the organization and developing a new, more effective vision (Warrilow, 2009).

According to this theory, at the initial stage, a transformational leader works with a group of people to identify organizational challenges and problems. Then develops a common vision, draws up a concrete action plan, and begins to make changes at the expense of inspiring and motivating other people employed in the existing organization (Klingborg et al., 2006).

Institutional managers who use the leadership transformational style to achieve specific results, focus on the individual level of motivation of the people employed in the organization, which plays an important role in shaping the overall organizational vision and achieving goals in a short period of time (Korejan et al., 2016).

Transformational leadership stands out from other concepts of leadership in terms of its complexity and the development of heterogeneous ways of solving the problem. In contrast to traditional leadership approaches, transformational leadership focuses on adapting and transforming an organization's behavior in ever-changing environmental conditions (Mohammed et al., 2018).

The concept of transformational leadership is particularly important in the context of the Georgian educational space, since the latter joined the Bologna Process in 2005, aiming at fundamental reform of the education system and bringing the Georgian educational space in line with the European educational space (Lezhava, 2016). In turn, the practice of effective leadership plays a crucial role in achieving the above goals.

\section{CONCLUSIONS AND RECOMMENDATIONS}

Leadership is a complex process. The leader has special qualities that stimulate him to motivate other individuals to implement the strategy. When talking about modern leadership practice, it is important to outline the key features of organizational performance. In this regard, formation of the culture and vision of the organization is essential.

One of the main purposes of modern leadership in organizational activities is to establish a common vision, attitudes and common cultural values.

When researching the characteristics and regularities of leadership, it is important to identify the characteristics of leaders' behavior, in particular, "employee orientation" and "production orientation". Whereas leaders who are production-oriented consider the fulfillment of the tasks set before them as a top priority. Based on the above, they consider employees only as a means to achieve a goal. However, as a rule, preference should be given to cooperation orientation.

In order to escape from the chaos created in the Georgian educational system in the post-Soviet period, it was extremely important to be actively involved in the Bologna process and to introduce the methods and practices that were actively used in European countries.

Transformational leadership stands out from other concepts of leadership in terms of its complexity and the development of heterogeneous ways of solving the problem. In contrast to traditional leadership approaches, transformational leadership focuses on adapting and transforming an organization's behavior in ever-changing environmental conditions.

\section{REFERENCES:}

Arnold, K. (2017). Transformational Leadership and Employee Psychological Well-Being: A Review and Directions for Future Research. Journal of Occupational Health Psychology. 22. 10.1037/ocp0000062.

Billig, M. (2014). Kurt Lewin's Leadership Studies and His Legacy to Social Psychology: Is There Nothing as Practical as a Good Theory?. Journal for the Theory of Social Behaviour. 45. 10.1111/jtsb.12074.

Bolden, R. (2004). What is Leadership?.

Breuilly, J. (2011). Max Weber, Charisma, and Nationalist Leadership. Nations and Nationalism. 17. 477 - 499. 10.1111/j.14698129.2011.00487.x.

Cai, D., Fink, E., \& Walker, C. (2019). Robert R. Blake, With Recognition of Jane S. Mouton. Negotiation and Conflict Management Research. 10.1111/ncmr.12151.

Civil Service Bureau. Management and leadership in public service.2020.

Eerkens, J., Vaughn, K. \& Kantner, J. (2010). Introduction: The Evolution of Leadership. https://www.researchgate.net/publication/257925411_Introduction_The_evolution_of_leadership ; Last Accessed: 01.08.2021

Hallinger, P. (2011). Leadership for Learning: Lessons from 40 Years of Empirical Research. Journal of Educational Administration. 49. 125-142. 10.1108/09578231111116699.

http://www.csb.gov.ge/media/3081/Mahagement-and-leadership-in public-service.pdf

https://www.researchgate.net/publication/29810622_What_is_Leadership ; Last Accessed: 01.08 .2021

https://www.researchgate.net/publication/305323677_Leadership_Theories_an_Overview_of_Early_Stages ; Last Accessed: 01.08.2021

Kikoria, G., Gachechiladze, S., \& Pataridze, S. (2019). Distance Education and E-learning in Georgia, 209-220. Economics and Business, XI, 2, 2019.

Klingborg, D., Moore, D., \& Varea-Hammond, S. (2006). What Is Leadership?. Journal of veterinary medical education. 33: 280283. 10.3138/jvme.33.2.280. 
Korejan, M., \& Shahbazi, H. (2016). An analysis of the Transformational Leadership Theory. Journal of Fundamental and Applied Sciences. 8:452. 10.4314/jfas.v8i3s.192. Last Accessed: 01.08.2021

Lezhava D., \& Amashukeli M. (2016). Assessing the Bologna Process in Georgia: Key Achievements and Challenges.Tbilisi. https://osgf.ge/files/2017/Bolonia-feradi-kdit.pdf ; Last Accessed: 01.08.2021

Madanchian, M., Norashikin, H., Noordin, F., \& Taherdoost, H. (2016). Leadership Theories; an Overview of Early Stages.

Raed, M., Nusari, M.; Ameen, A,. \& Alrajawy, I. (2018). Leadership in the organization: A Conceptual Review. 2. 52-59. Last Accessed: 01.08.2021

Takala, T. (1998). Plato on Leadership. Journal of Business Ethics - J BUS ETHICS. 17:785-798. 